\title{
South Africa: \\ 'Who Stole my Passengers?. Uber Cabs, Metered Taxis and the Search for Common Ground
}

\author{
Joseph Olusegun ADEBAYO
}

\begin{abstract}
When Uber Cab services started in 2009 as a 'tap-a-button-get a ride' idea of moving from one point to the other easily, little did the founders know it would grow into one of the biggest start-ups in the world in such a short time. Uber has revolutionised the cab industry by introducing an app that gets people rides from 'simple taps'. Although there are many positives from Uber's emergence, it is imperative to note that its rapid growth across the globe has caused frictions with metered taxi operators who have existed in the cab business milieu several years earlier. In most major cities of the world where Uber is operational, there have been some degrees of revolt and even violence between Uber drivers and metered taxi operators. The metered taxi operators cite grievances such as the use of unlicensed drivers by Uber, unfair competition and the 'stealing' of their passengers. Since Uber's 2013 launch in South Africa, there have been growing clashes between the platform and metered taxi operators with incessant disruptions to services, injuries and deaths, as well as damages to cars. This study examines the recurring conflict between Uber cab drivers and metered taxi operators within the Cape Town area of South Africa with the aim to proffering, from the aggrieved and affected drivers, effective conflict management strategies to mitigate the seemingly protracted conflict.
\end{abstract}

Keywords: conflict, conflict management, common ground, relative deprivation, frustration, aggression.

Joseph Olusegun ADEBAYO, Ph.D.

Centre for African Studies

The University of Cape Town,

Rondebosch, South Africa

Email: joseph.adebayo@uct.ac.za

Conflict Studies Quarterly

Issue 27, April 2019, pp. 3-20

DOI:10.24193/csq.27.1

Published First Online: 01/04/2019

\section{Introduction/Background}

The importance of effective transportation systems to the socioeconomic development of cities and nations cannot be overemphasized. Rising global population and increase in movements of humans, goods, and services mean that cities are constantly evolving innovative methods of ensuring that increasing demands for efficient, effective and affordable transportation are 
adequately met. No nation desirous of sustainable growth and development can afford to overlook the immense impact transportation has on the process. Effective transportation, whether public or private, is a major means to access employment, education and public services. Thus, it can be argued that effective transportation is germane to socioeconomic growth and development. Sadly, Berg, Deichmann, Liu and Selod (2017) state that poorer economies still grapple with the challenge of moving humans, goods and services from one place to the other due to significant backlogs of transport infrastructure investments in both rural and urban areas, weak governance, inadequate regulations in the transport sector and rising social cost in terms of congestion, pollution and accidents.

Advancements over the last few decades have significantly redefined global transportation systems. In more advanced economies, investments in the transportation sector and improvements in technology have led to continuous decline in transportation costs, ease of locating means of production and improved comfort which has translated to stimulated growth and economic development (Pojani \& Stead, 2015). One of such advancements in cab transportation in the last decade is the Uber cab which was founded by Garrett Camp and Travis Kalanick in 2009. The duo, on a cold Paris night in 2008, had struggled to successful hail a cab, so they came up with the idea that has today revolutionised cab transportation. They developed an app that allows prospective riders to request a ride, know in advance the possible cost and travel time, as well as place advance bookings. According to Burger-Smidt and Wickins (2016) Uber matches riders (passengers to be transported from one point to another) with drivers (drivers who operate vehicles of various specifications as quasi taxis but who initially did not accept payment directly from the passenger) through the use of an application (as an "app") used on smartphone devices. The service offers great convenience to both passengers and drivers, amongst others, in relation to payment method, time-saving and efficiency of use.

Although Uber's emergence has been largely hailed as progressive, it has nonetheless experienced varying degrees of conflicts with governments and rival taxi companies in most of the countries where they operate. In 2016, several Uber cars were torched and drivers injured as metered taxi operators in Nairobi, Kenya's capital, protested against what they referred to as Uber's 'unfair advantage'. According to Mohammed (2016), at the peak of the protests, the Kenyan United Taxi Organisation (KUTO) promised to completely shut down Uber in the country if the relevant authorities failed to heed to their demands for 'equal playing ground'. Similarly, in Germany, the conflict with the government led to the banning of Uber in the city of Berlin in April 2014 on passenger safety grounds. German officials said Uber did not do enough to protect its passengers from unlicensed drivers. Uber's response was that it does not operate a taxi service, but merely offers a platform that mediates between drivers and customers. In other major 
European cities, such as Madrid, London, and Paris, there have been major demonstrations against the company. In Cape Town, the study area, there have been persistent conflicts between Uber cab drivers, rival taxi operators, and the government. Between January and June 2016 for example, Van Zyl (2016) claims that over 300 Uber cabs were impounded by the City of Cape Town's Transport and Urban Development Authority. There have also been increased cases of violent attacks on Uber drivers by metered taxi operators in the city with reports of drivers been beaten up and their cars damaged.

Attempts in the past to resolve the protracted crises have not yielded the desired results. For example, in July 2017, the Premier of South Africa's Gauteng Province, David Makhura, assured that law enforcement agencies would be deployed to all the identified hotspots where Uber operates across the Province. Spe aking further on the crises, the Premier stated thus:

"We want a dedicated special task force to look at this conflict, especially the use of violence by those who are involved in this. The introduction of the special task force is a different thing. We know police have a lot on their hands. The reason we have decided we need a special task force is that we will have a dedicated police team to deal with this crime" (Rawlins, 2017).

Similarly, former Police Minister, Mr. Fikile Mbalula, warned that perpetrators would be severely dealt with and that more policemen and women would be deployed to trouble spots to curb the violence and ensure 'peace'. The Minister stated thus:

“The metered taxi drivers need to understand that they've got no right to take the law into their hands and do what they are doing. We are intervening heavily..."We understand the challenges that metered taxi drivers are going through and the issues they are dealing with, that's why we want to understand from the Department of Transport what exactly they are dealing with. Largely at the centre of this violence is competition" (Bateman, 2017).

A similar top-down, clampdown and militarized approach to resolving the conflict has also been applied in the Western Cape Province. The problem with such an approach to 'peace' is that it is often not sustainable. At best, it produces what renowned peace scholar Johan Galtung refers to as negative peace. Galtung (1969) describes negative peace as simply the absence of conflict, whereas positive peace consists of conditions where justice, equity, harmony, etc., can flourish. Even the former Transport Minister, Joe Maswanganyi, acknowledged that the conflict resolution/management approaches employed by the central government and Provinces were unsustainable. During the Southern African Transport Conference (SATCO) held July 2017 in Pretoria, the Minister remarked thus:

“...The taxi industry does not want Uber. I said to them, 'Why don't you digitalize your industry?' We can't resist change; we have to move with it. I admit 
that the police's intervention, whenever there was taxi violence, would not bring about a lasting solution to the problem..." (Moatshe, 2017).

\section{Justification for the Study}

Herein is the justification for this study. To the best of the researcher's knowledge, there is a dearth of academic research on the Uber/metered taxi crises; it is almost non-existent. This study hopes to fill this gap. Also, as can be seen from some of the conflict management/resolution interventions listed above, the approaches have largely been top-down, with little attention paid to drivers on both sides as possible brokers or sources of solution. The problem with a top-down approach to conflict resolution is that it often lacks legitimacy and ownership in the eyes of key stakeholders (in this case drivers and platform partners), thereby prohibiting meaningful and lasting resolution (Khadka \& Vacik, 2012). The study adopted a bottom-top approach to proffering a durable solution to the protracted crises by presenting the views and suggestions for resolution from the drivers themselves, who are often the most affected.

\section{Methodology}

This study critically examines the protracted conflict with a view toproffering durable and sustainable solution from the standpoint of drivers from both Uber and metered taxi platforms. Given the formative and exploratory nature of the study, a qualitative research methodology was adopted. The researcher interviewed 60 Uber cab drivers and 60 metered taxi drivers for a period of six months (from February to July 2017), through purposive sampling technique. As Patton (2002) notes, this sampling technique, widely used in qualitative research, is appropriate in identifying and selecting 'information-rich' cases for the most effective use of limited resources, by identifying and selecting individuals or groups that are especially knowledgeable and experienced about or with a phenomenon of interest. Bernard (2002) and Spradley (1979) state that participant identification and selection should not be limited to knowledge and experience alone. They advise that other factors such as availability and willingness to participate in the study, as well as the ability to communicate experiences and opinions in an articulate, expressive and reflective manner, should be taken into consideration. All these factors were taken into consideration by the researcher when determining the participants for the study.

\section{The How}

The researcher requested Uber rides and after that told the drivers he was conducting a study and would require them to answer certain questions as honestly as possible. The same process was employed with metered taxi drivers; only this time, the researcher had to randomly order a ride from a metered taxi company and after that asked them whether or not they were up for an interview. The researcher made it clear that it was 
voluntary and that they were not obliged to speak. Suffice to add that the researcher limited the research to Uber cabs only and did not include Taxify, the other tap-and-go cab operator in the city. This is because Taxify's operation was still new (or relaunched) in the city, and also because most of the Uber drivers were concurrently registered with Taxify. Most drivers confirmed that they were registered for both services at the same time and respond to whichever notify them first. On the metered taxi side, the researcher involved drivers from Cabco, Excite Taxis, Intercab, and Unicab. The metered taxi operators were chosen because of their spread across the city, their relatively cheap fares (averagely R8.80/kilometre) and their reputation for good service.

\section{Biographical Data of Respondents}

As earlier stated, the study involved 120 participants in total (60 drivers each from both the metered and Uber platform). Although the researcher did not deliberately delineate or profile them along with any racial, gender or ethno-religious lines, it nonetheless played out during the interview sessions. The most significant of these data, as would be discussed later in the study, is the nationality of the drivers; many of the Uber cabdrivers attributed the attacks on the fact that they were 'foreigners', while South African drivers claimed the Uber platform is skewed in such a way as to wittingly or unwittingly favour non-South Africans.

\section{Drivers' Sex}

Table 1: Respondents' sex Source: Fieldwork

\begin{tabular}{clcc}
\hline S/N & \multicolumn{1}{c}{ Sex } & Total & Percentage (\%) \\
\hline 1. & Male & 103 & 86 \\
2. & Female & 17 & 14 \\
3. & TOTAL & 120 & 100 \\
\hline
\end{tabular}

Expectedly, as can be seen from table 1 above, 103 of the respondents (86\%) were male, while $17(14 \%)$ were female. Suffice to add that the researcher's choice of the word 'expectedly' was deliberate, but not endorsements of the discrimination females face in the transport industry. All across the globe, the percentage of female cab drivers as compared to males is staggeringly low. In the US for example, Sherman (2018) claims that just 14 percent of cab drivers are female. The gender disparity is even significantly smaller in Cape Town, the study area. Despite the fact that women are, statistically speaking, safer drivers, female cab drivers are always ominously lower in number than their male equals. According to Social Issues Research Centre (SIRC, 2004), differences between men and women in terms of their driving behaviour and accident rates have long been demonstrated in the UK, mainland Europe, the United States, Australia and in many other countries. In all studies and analyses, without exception, men have been shown to have a higher rate of car crashes than women. It is thus inexplicable that 
women are blatantly marginalized in the transport industry. Suffice to add that efforts have been made in the past in South Africa to correct the male-female imbalance in the transport industry, especially regarding the number of female drivers. For example, in 2013, the South African National Taxi Council (SANTACO) embarked on an ambitious project to train 1000 female drivers in an aggressive drive to encourage not only becoming drivers but also joining its management structure as shareholders.

\section{Drivers' Age}

Table 2: Drivers' age range Source: Fieldwork

\begin{tabular}{lcc}
\hline \multicolumn{1}{c}{ Age Range } & Frequency & Percentage (\%) \\
\hline $20-30$ & 21 & 18 \\
$30-40$ & 46 & 38 \\
$40-50$ & 24 & 20 \\
Above 50 & 29 & 24 \\
\hline TOTAL & 120 & 100 \\
\hline
\end{tabular}

As can be seen from table 2 above, a sizeable number of the selected drivers ( 38 percent) were within the age range $30-40,24$ percent were aged 50 and above, 24 percent were aged 40-50, while 18 percent were aged 20-30.

\section{Drivers' Nationalities}

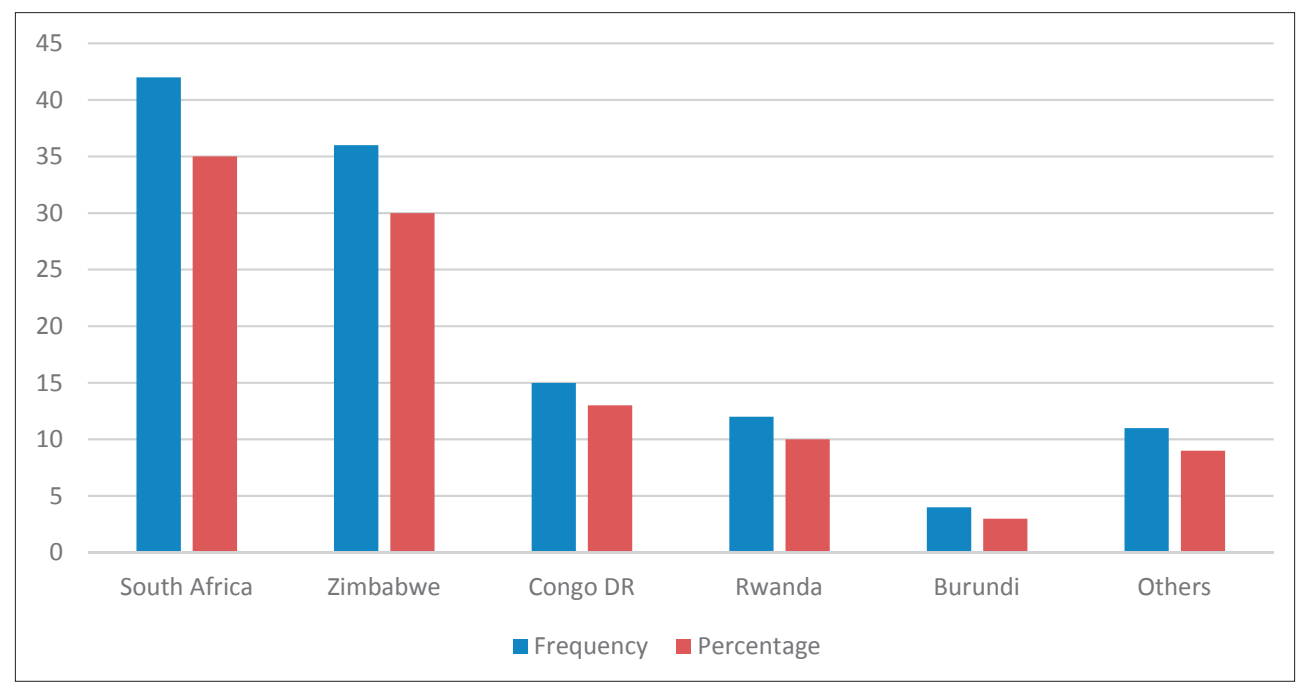

Figure 1: Drivers' nationality Source: Fieldwork

One of the most contentious discourses in the Uber/metered taxi debacle during the course of the interviews was the nationality of the selected drivers. As can be gleaned 
from Table 3 above, 42 of the sampled drivers are South Africans, 36 are Zimbabweans, 15 are from the Democratic Republic of Congo, 12 are from Rwanda, while 4 are from Burundi. 11 drivers were also interviewed from the following countries: Somalia (2), Kenya (3), Pakistan (2), Nigeria (2) and Cameroun (2).

\section{Theoretical underpinnings:}

\section{from a sense of relative deprivation to frustration aggression.}

\section{Relative Deprivation Theory}

One of the most misunderstood concepts in societal discourse is conflict; this is because of its ubiquitous and very insidious nature which makes it easy for people to give it different meanings and connotations, depending on who is using it, and/or where it is been used. According to McShanne and Glinow (2008), conflict generates considerable ambivalence and leaves many scholars and administrators quite uncertain about (1) its meaning and relevance; and (2) how best to cope with it. Although there are many definitions of conflict, Robbins's (1974) definition is closely related to this study. He defines the conflict like a process that begins where one party perceives that another party has negatively affected, or is about to negatively affects something that the first party cares about. This is a very apt definition emphasizing that conflict is about perception not necessarily real hard facts. It points to the emotional nature of the conflict, by referring to a word like care (Robbins, 1974).

The major concern (or perception) amongst metered taxi operators is that the Uber cabs have negatively impacted on their revenues by 'stealing' their passengers. Robin believes conflicts mainly result from perceptions, more than reality. Throughout this study, drivers on both sides (Uber and metered taxis) made unfounded claims, mainly based on perceptions about how the other party was delimiting their business interests. It is these perceptions that often lead to feelings of relative deprivation, which often give birth to frustrations, which may ultimately result in aggression.

First documented by Stouffer, Suchman, DeVinney, Star and Williams (1949), the relative deprivation theory posits that when one's standing is relatively disadvantaged, and when that individual or group perceive that the disadvantage is undeserved, it may lead to the feeling of personal (or group) relative deprivation. The relative deprivation theory aptly explains the conflict between Uber cab and metered taxis in the study area. Smith, Pettigrew, Pippin and Bialosiewicz (2012) define relative derivation as the perception by individuals or groups that they are worse off compared to others when certain standards are measured. This feeling is often accompanied by anger, resentment and sometimes violence. Feelings of relative deprivation result when individuals compare their own circumstance(s) with someone else's situation or a cognitive standard such as equity or justice and perceive that they are not receiving what they merit. Relative 
deprivation can also be experienced at the group level because groups' experiences can become relevant to one's own personal experience. For example, metered taxi drivers feel a deep sense of group deprivation, which has spiraled down to individual drivers. Thus, metered taxi operators who perceive that they are relatively deprived at individual and group levels are the most motivated to participate in a protest action against Uber cab drivers.

In one of my interviews with the selected drivers, one driver's comments aptly describe this feeling of relative deprivation that most drivers feel. When asked why metered cab drivers 'attack' Uber cab drivers, the driver responded thus:

"Look, my brother, these Uber guys deliberately incite us to anger. Look around you, there are many metered cabs packed without passengers, yet an Uber guy would come and pack at the same place we are parked and before you know it, he gets a passenger. That is why we don't want them to park their cars close to ours; they are deliberately stealing the few passengers that we manage to get. The people you see patronizing us are those who cannot get through to Uber or who do not have cheque accounts. Now that Uber has introduced cash payments, the situation has even become worse as a lot of people now prefer Uber cabs to us. We have suddenly become alternatives" (personal communication, Floyd).

\section{Is Relative Deprivation a Prelude to Frustration-Aggression?}

Dollard, Miller, Doob, Mowrer and Sears (1939) are credited to have been the first to put forward the frustration-aggression hypothesis. In 1939, they published a monograph on aggression which immensely impacted the Western discourse on aggression more than any article at that time. For more than seven decades, the frustration-aggression hypothesis has guided, in one way or another, the better part of the experimental research on human aggression. The theory, as put forward by Dollard et al. (1939), seems to provide justification for aggressive behaviours in individuals or groups with a common phrase been: 'being aggressive made me do it!. Zilmann (1979) argues that the theory provides a ready alibi for uncontrolled (or premeditated) hostile or aggressive actions.

The link between a feeling of relative deprivation and aggressive behaviour has been well-researched over the years. For example, Smith, Pettigrew, Pippin and Bialosiewicz (2012), in their study, outlined the following experience of relative deprivation that 'graduates' to frustration, and then aggression:

“...An individual's objective position in a social hierarchy evokes a comparison process, with the experience of disadvantage stemming from an interpersonal comparison between the individual and other persons that are better off. As a consequence, the individual responds with anger and resentment to the 
undeserved disadvantage. These emotional reactions, in turn, could evoke aggressive or violent activities. That is, this model proposes a direct link between the experience of disadvantage and hostile emotional reactions, whereas the experience of disadvantage is indirectly related (via hostile emotions) to aggressive behaviour" (p.116).

In a study conducted by Sagioglou and Greitemeyer (2017), they found that the experience of personal relative deprivation causally increases the propensity for aggressive behaviour. In separate experiments involving 482 participants ( 244 females, 237 males; mean age $=36.4$ years, $\mathrm{SD}=12.9$ ), they found consistent evidence for this concept. Their study found that personal relative deprivation causes an increase in aggression rather than personal relative gratification causing a decrease in gratification. They also found that this increase in aggressive behaviour seems to be directed only toward those that were perceived to be the source of participants' experience of disadvantage. This position correlates with the nature of attacks in the Cape Town area as Uber cab drivers were the main subjects of the attacks and not their passengers, although some passengers get caught up in the ensuing skirmish. According to their reports, although personal relative deprivation increased state hostility, they did not found that people experiencing personal relative deprivation became more aggressive toward another person who was not responsible for the feedback. In contrast, Greitemeyer and Sagioglou (2016) showed that low SES increased aggression toward the source of participants' disadvantage but also toward a neutral target. Nevertheless, in the present context, it appeared that people experiencing personal relative deprivation were able to fully with hold their hostile feelings when confronted with an uninvolved party. When given the chance to retaliate against the source of their anger, however, their hostile affect seems to evoke aggressive behaviour (Greitemeyer \& Sagioglou, 2016).

\section{Voices from the wheels: towards a 'bottom-top' approach to resolving the Uber/metered taxi crisis.}

The 'bottom-up' approach to peacebuilding has gained immense relevance since the 1990s. According to Lefranc (2009), the approach has been frequently integrated into mainstream development programmes by specialised Non-Governmental Organisations (NGOs) such as Search for Common Ground, Conflict Management Group, Conciliation Resources, Interpeace, etc. Over the years, peace practitioners have realised the significance of the bottom-up approach to conflict resolution and the international 'successes' may be partly due to the fact that they represent viable alternatives to dominant modes of intervention.

As stated in the methodology section of this study, the researcher conducted a qualitative research that involved interviews with selected Uber and metered taxi drivers. In this section, their responses, vis-à-vis solutions preferred are presented. Some of the 
questions posed to the drivers are:

a. What are the underlying factors for the protracted conflict between Uber and metered taxi drivers?

b. Do you think that the conflict management/resolution techniques adopted have been successful?

c. Can you kindly suggest sustainable conflict resolution techniques for the crisis?

\section{What are the underlying causal factors for the protracted conflict between Uber and metered cab drivers?}

Many reasons have been adduced for the lingering Uber/metered taxi conflict and some of them have been listed in the introductory section of this study. What the researcher sought to determine from the drivers was the possibility of finding out other reasons for the conflict that have not been mentioned in public discourse. Thus, the researcher asked the drivers for their own opinions of what the causal factors for the conflict are and some of their responses were quite interesting. Suffice to add that pseudonyms have been used instead of drivers' actual names to protect their identities. Some of the foreign Uber drivers claimed the attacks meted at them were simply extensions of the larger xenophobic attacks meted against foreigners. One driver had this to say about the attacks.

"I know there are claims that Uber cabs are cutting metered taxis' profits and stealing their passengers, but that is not the main reason. Let me tell you, they are attacking us because we are foreigners. As you must have observed, most of the Uber drivers are non-South Africans. What happens is that metered taxi drivers speak a local language to you and when you cannot answer back in that language, they become furious and attack you. I doubt the problem is economic as claimed, it is purely xenophobic. Whenever there is a conflict, you will notice that the traffic police take sides with the metered taxi guys because they consist mainly of nationals" (personal communication, Alex).

Alex's claims that the attacks were xenophobic were countered by most South African metered taxi drivers. Khumalo, one of the sampled metered taxi drivers stated that the Uber platform has made the entire cab business unprofitable; thereby making a lot of metered taxi drivers quit the business entirely. The driver remarked thus:

"Claims by Uber drivers that the attacks are xenophobic is outrageous and downright cheap. It seems claims of xenophobia have become the new alibi for foreign nationals who either break the laws or who feel competitively threatened. Tell me, there have been several taxi clashes in the townships across the nooks and crannies of this country, how many of the taxi drivers are foreigners? When you threaten a man's livelihood, he will charge at you; 
it doesn't matter whether you are black, white, foreigner or local. Hunger has no identity" (personal communication, Khumalo).

Drivers on both divides provided different opinions on whether or not they thought the attacks were xenophobic, with most foreign Uber drivers claiming the attacks were xenophobic, while most South African metered taxi drivers claim their grouses were purely economic and nothing more. It is imperative to state here that taxi industry violence in South Africa predates Uber, and claims of xenophobia may be more perceived, than reality. At the tail 'end' of the apartheid era, Bell and Armytage (2017) recall that hundreds of people were killed in 'taxi turf wars' between taxi associations and individual minibus taxi drivers. The 'war', which involved mainly South African nationals on both sides, led to deaths and loss of property as rival cartels sought to defend their market share. While a feeling of relative deprivation can indeed fuel aggressive xenophobic behaviour as stated by Greitemeyer and Sagioglou (2016), that aggressive behaviouris often targeted at the perceived source(s) of deprivation, irrespective of creed, colour, and nationality.

Another standout reason cited for the conflict by the interviewed drivers was claimed by metered taxi operators that Uber's requirements make it difficult for South African nationals to be partners and drivers. Some of the interviewed metered cabs drivers complained that they are often required to meet stringent conditions and that their credits records are scrutinized and if their records are not up to date, they are often denied partnership. They (metered taxi drivers) wonder how foreign nationals 'easily' get approved as drivers without required permits and licenses, whereas they (S.A. nationals) are made to undergo credit checks and several other near-impossible requirements. Senzo, one of the metered taxi drivers had this to say:

"I am always amazed at the number of non-South African drivers on the Uber platform. Listen, I do not have any problems with foreigners making legit living in the country, after all, we are all Africans and I strongly advocate and stand for Ubuntu. My only problem is that most of these drivers do not have residence permits. That should be basic, isn't it? How does a man or woman without valid residence permit venture into a business that threatens the livelihoods of another and expects that man or woman not to react? Not only that, if you notice, the drivers do not have driver'slicense and the required permits from the transport department. That is to tell you that Uber is breaking our laws just to make profits. It is unacceptable" (personal communication, Senzo).

I asked some Uber drivers what they thought of Senzo's claims. Wallace, one of the drivers, had this to say:

"I must admit that some of our drivers do not possess the requisite permits, including residence permits; but it is not deliberate. You must understand 
that most of these drivers actually drive for South African nationals who have several cars on the platform. They just want men/women who would work hard enough to help them make profits and that's how we find ourselves here. I must state however that most of us have permits now" (personal communication, Wallace).

Uber provides a lot of non-South African nationals 'shortcuts' to employment that they would ordinarily not be able to get in other sectors of the economy because of stringent requirements. According to Bell and Armytage (2017), the company's flexible requirements have made it easy for a lot of people to register as drivers. Many of the 'foreign' drivers meet Uber's background checks, car, and driving checks, and so can earn a living as drivers in South Africa's urban centres. This has only turned Uber into a flashpoint for existing tensions over employment and wages.

\section{Do you think that the conflict management/resolution techniques adopted have been successful?}

Most of the drivers interviewed remarked that the conflict management techniques adopted for the resolution of the conflict have not been successful. The researcher sought to find out why the drivers felt the strategies failed to ensure long-lasting resolution of the conflict and some of their responses are presented in this section.

The central reason adduced by the drivers for the 'failure' of previous attempts to resolve the conflict is the non-inclusion of drivers from both the Uber and metered taxi divides in the peacebuilding and conflict management process. The drivers say they are only told decisions that have been taken, without any inputs from them. Jean-Paul, one of the interviewed Uber drivers, remarked thus:

"The problem is that we have Uber partners whose main concern is profit. Some of them have so many cars on the platform and only meet the drivers when it's time to 'share' profits. They do not know what we go through on the roads daily. However, when there are meetings geared at resolving conflicts, it is the management and some high-ranking partners that meet. What happened to the guy who drives with fear of being attacked? Surely, a way of incorporating our suggestions must be worked out if we must achieve a lasting solution to this problem" (personal communication, Jean-Paul).

Jean-Paul's position is corroborated by Vuyo, a metered taxi driver. He was of the opinion that drivers' inputs should be taken into consideration when formulating solutions for the conflict. He further remarked thus:

"Have you noticed that whenever there is a clash, the government sends police officers to suppress the conflict? This measure is only reactive and does not achieve lasting peace. Also, when there is a semblance of quiet, nothing is 
heard from the transport department on efforts to permanently resolve the conflict until there is another attack; this should not be the case. I think it is very important that they consult us on what we think should be action steps for lasting solutions. Nobody understands the situation like we the drivers; no matter how much people claim to understand, you have to be on the road to know what we go through daily" (personal communication, Vuyo).

It is pertinent to note that most of the sampled drivers (especially those on the Uber platform), averred that they have severally been asked to suggest conflict management strategies, albeit via email messages. They argue that although some of them send e-mails to the management, they doubt their suggestions are given any attention considering the protracted nature of the crisis. One driver, Lungisile had this to say:

"One of our major desires is to have a face-to-face meeting with metered cab drivers so that we can iron out issues as friends and colleagues. Believe me, we are actually friends; some of us have friends and brothers who are metered cab drivers. The problem is that the drivers from the metered cab side have severally refused to meet with us. We have stated this severally in our emails but have not received any positive feedback. We want the management of both Uber and metered cab platforms to facilitate this meeting" (personal communication, Lungisile).

\section{Can you suggest sustainable conflict resolution techniques for the crisis?}

The general feeling amongst the sampled drivers on both sides was that the conflict management strategies have not been effective enough to stem the violence or provide a lasting solution to the conflict. Thus, the researcher asked the drivers to suggest how to achieve durable resolution of the protracted crisis. Their responses were quite intriguing.

All the Uber drivers interviewed averred that Uber should make the process of joining the platform a lot easier so that a lot of metered taxi drivers can join the platform. One Uber driver, Brandon noted thus:

"I think one of the problems we are facing is that many metered cab drivers want to join the Uber platform but they cannot because of the stringent demands. For example, the criminal check automatically disqualifies you if your records are not good. Foreign nationals beat this demand because most of them have not stayed here long enough to have committed serious crimes. Let me give you an example: I have a very dear friend of mine who was arrested for housebreaking when we were in high school. Do you know that the crime has made it almost impossible for him to join the platform? I am talking about a crime he committed almost 15 years ago. You see, that is why it seems as if 
the platform favours non-South Africans, it is a very complicated situation" (personal communication, Brandon).

Edward, a metered cab driver corroborated Brandon's position that the process for joining the Uber platform is a little bit too stringent and should be reviewed. He remarked thus:

"People ask: why don't you join the Uber platform if metered cabs are unprofitable? I tell them that it is not as easy as they think. When you go to make inquiries, they ask you for documents that are difficult to obtain and then there is the criminal check. Nobody is saying criminal checks should not be carried out, it should. Sadly, many people have been refused an operational license because of 'petty' crimes they committed years ago. I think that the platform is designed in such a way as to just automatically bounce you off if you are found to have criminal records, you are not given the opportunity to probably provide clarity. If they can make it a lot easier to join, maybe many of us would join" (personal communication, Edward).

Another requirement noted by the drivers was the issue of vehicle requirements. According to the company's South African website (https://www.uber.com/en-ZA/ drive/requirements), all vehicles need to be in excellent working and physical condition. Additionally, all vehicles must have the following:

- A working radio

- Air conditioning

- Four doors

- No hatchbacks accepted.

- All vehicles must be 2013 or newer.

The above requirements, according to most of the sampled metered taxi operators, make it difficult for drivers to convert their cars into the Uber platform. They argue that even when they get financed by the bank, it would take at least five years to pay off the loan, by which time the cars would have reduced in value due to wear and tear. Sbonelo, a metered taxi driver remarked thus:

"Uber's requirements are okay, they are entitled to how they want to run their business. The problem, however, is that it suffocates people like me who cannot afford the quality of cars they require. The banks sell the cars to you for astronomical prices and then you are 'forced' by the platform to charge fares as low as R20. How do you pay off a car loan of R220, 000 with R20 fares? You have the alternative of working for someone and then agreeing on a payment plan, but that can also be enslaving. You see, it is a complicated issue" (personal communication, Sbonelo). 
Wright, an Uber driver, however, presented another angle to the argument. He was of the opinion that although he agrees that Uber's requirements are inflexible, they are nonetheless important. He contends that most metered cab drivers are not patient enough to build money gradually. He stated that although the money is 'small', it, however, adds up before long:

"My brother, the metered taxi guys think we make loads of money with little efforts, but they are actually wrong. Although I agree that we have more clients than the metered taxi guys, but we actually work twice as hard as they do. For example, the Uber app charges R21 for a trip that the metered taxi could possibly charge R53. We undertake more trips than metered taxi operators and even work very long hours before we are able to break even. I also think that there are several schemes out there that allow drivers get cars and pay in little installments. Infact, I am aware that Bidvest Bank offers a type of car borrowing scheme where you can borrow cars from them and use. I don't know the details though" (personal communication, Wright).

Another central theme that emerged during the interviews was the issue of fare costs. All the interviewed metered cab drivers complained that Uber's charges make it impossible for them to compete. They posit that although they agree that businesses have a right to operate in ways that they deem fit, they nonetheless said it is important to regulate fares so that thousands would not be left hungry without sources of income. Nomvula one of the metered cab drivers remarked thus:

"I really do not understand how our colleagues on the Uber platform make profits. Can you imagine that a trip that we normally would charge R50 can go for as little as R21 on Uber? Do you now see why passengers prefer Uber to us? My cab company for instance charges R8.8 per kilometre, still we charge way below Uber. This is killing us literally, there should be a cap on the amount cabs can charge, the playing ground should be level please. What do you want us to do, quit completely? Can we all possibly be Uber drivers? Is that even realistically possible?" (personal communication, Nomvula).

Even Uber drivers agree that their fares are low and that they have to work twice as hard as metered cab drivers to be able to break even and/or make a profit. Austin, an Uber driver, made comments that were similar to those raised by Wright above who remarked that Uber drivers actually work twice as hard as metered cab drivers and that the belief that they actually make more profits could just be a perception and not reality:

"It is sad that the issue of 'clients' stealing' and fares have caused immense loss to both Uber drivers and our colleagues on the metered taxi side. The truth is, we are both suffering and the entire transport industry should be regulated. For example, Uber takes $25 \%$ of your trip fares, the owner of the car, if it is 
not yours, takes R2500 or R3000 weekly depending on your agreement, then there is the challenge of very low fares. How do you think we survive? It is only those who own their own cars that actually have it a little good; the rest of us just barely survive. While I agree that the fares Uber charges affect metered cab drivers, I nonetheless do not think they are the only ones who are affected, we are in this together" (personal communication, Austin).

\section{Conclusion and Recommendations}

I went into the study not knowing what I might come across; I love such studies because they are what the humanities are all about-studying people in their everyday lives and unraveling their uniqueness. Unlike the sciences where you are 'very sure' that sodium $(\mathrm{Na})+$ chloride $(\mathrm{Cl})$ would 'definitely' give you sodium chloride $(\mathrm{NaCl})$, the same cannot be said with regards to studies involving humans, because no two humans are the same, no matter how similar their socio-cultural, socioeconomic and sociopolitical milieus. The study's findings confirmed that.

One main theme that emerged all through the study was the fear of change, both in the now and in the future. Most of the metered taxi drivers agreed that they still made reasonable profits, but were scared that they would soon be driven out of business completely in the future by Uber, Taxify and other 'tap-a-button-get-a-ride' companies. The truth, however, is that change is inevitable and the issues raised to reflect the deep-seated feeling of inequality and relative deprivation that permeates the country. Claims of xenophobia by most of the interviewed Uber drivers who were non-South Africans may not be implausible. The widening gap between the rich and the poor and rising unemployment rates mean that people would feel relatively deprived if they are out of job, while 'the other' (in this case a foreigner) is gainfully employed. In fact, it doesn't matter whether or not the unemployed individual has the capacity to do the job 'the other' does, he is just angry that 'the other' get to live better than him in his own country. This feeling of relative deprivation can even be potentially violent if the 'deprived' individual (in this case the metered cab driver) can physically identify the reason for his perceived deprivation (Uber cab drivers).

Regulatory issues were also raised by drivers on both sides. Metered cab drivers argued that most Uber cab drivers operated without requisite permits. For example, a 2016 report by Van Zyl claimed that most of Uber's estimated 2000 Cape Town drivers operated without metered taxi permits and thus were operating illegally. Given that the issue is one of the major bone of contention, it becomes very imperative for the relevant authorities to either facilitate quick processing of permits for deserving drivers or clampdown on erring drivers. The Department of Transportation must be seen to be fair to all parties involved, and fairness means no party should feel victimized or institutionally relatively deprived. In 2016, the South African cabinet approved the 
National Land Transport Amendment Bill which regards Uber operators as metered taxi operators. Thus, it is expected that they operate within the ambits of the law and constitutional provisions.

It is also very imperative for metered taxi operators to adjust services and fares in the face of competition because it is inevitable. Many African transportation companies have begun offering various forms of incentives to drivers and passengers in a bid to stay afloat. For example, reacting to complaints of shortchanging by Uber drivers in South Africa, Africa Ride announced its more than 500 drivers would be given a larger stake in the business. Similarly, in 2017, South Africa-based startup Where Is My Transport launched its transport for Cape Town app, which provides information for those planning journeys, including timetables, traffic incidents and places of interest.

\section{References}

1. Bateman, B. (2017). Mbalula: We're intervening heavily in Uber, metered taxi drivers feud. Eye Witness News. Retrieved from http://ewn.co.za/2017/07/18/mbalula-were-intervening-heavily-in-uber-metered-taxi-drivers-feud.

2. Bell, M., \& Armytage, R. (2017, September 16). What the violent 'Uber wars' tell us about Zuma's South Africa. The Independent Newspaper. Retrieved from http://www. independent.co.uk/news/world/africa/what-the-violent-uber-wars-tell-us-aboutzumas-south-africa-a7948496.html.

3. Bernard, H. (2002). Research methods in anthropology: Qualitative and quantitative approaches. Walnut Creek, CA: Alta Mira Press.

4. Berg, C., Deichmann, U., Liu, Y., \& Selod, H. (2017). Transport Policies and Development. The Journal of Development Studies, 53(4), 465-480.

5. Burger-Smidt, A., \& Wickins, G. (2016). The Uber Price-Fixing Ride: What Are the Antitrust Co-Ordinates? Johannesburg: Werksmans Advisory Services.

6. Dollard, J., Miller, N. E., Doob, L. W., Mowrer, O. H., \& Sears, R. R. (1939). Frustration and aggression. New Haven: Yale University Press.

7. Galtung, J. (1969). Violence, Peace, and Peace Research. Journal of Peace Research, 6(3), 167-191.

8. Khadka, C., \& Vacik, H. (2012). Comparing a top-down and bottom-up approach in the identification of criteria and indicators for sustainable community forest management in Nepal. Forestry: An International Journal of Forest Research, 85(1), 145-158.

9. Lefranc S. (2009). La professionnalisation d'un militantisme réformateur du droit: l'invention de la justice transitionnelle. Droit et société, 73, 561-589.

10. Moatshe, R. (2017, July 11). Minister urges scientific approach to end Uber-taxi war. Pretoria News. Retrieved from https://www.iol.co.za/pretoria-news/minister-urgesscientific-approach-to-end-uber-taxi-war-10234001.

11. Mohammed, 0. (2016, February 4). Nairobi taxi drivers are trying to shut down Uber with protests and intimidation. Quartz Africa. Retrieved from https://qz.com/608977/ nairobi-taxi-drivers-are-trying-to-shut-down-uber-with-protests-and-intimidation/. 
12. McShane, S,. \& Glinow, M. (2008). Organizational Behaviour. Columbus, OH: McGraw Hill.

13. Patton, M. (2002). Qualitative research and evaluation methods. Thousand Oaks: Sage Publications.

14. Pojani, D., \& Stead, D. (2015). Sustainable Urban Transport in the Developing World: Beyond Megacities. Sustainability, 7, 7784-7805. DOI: 10.3390/su7067784.

15. Rawlins, K. (2017, September 18). Gauteng moves to curb Uber, metered taxi violence. IT Web. Retrieved from https://www.itweb.co.za/content/zKWEBb7yXjjvmRjO.

16. Robbins, S. (1974). Managing organizational conflict: A Non-Traditional Approach. Englewood Cliffs: Prentice Hall.

17. Sagioglou, C., \& Greitemeyer, T. (2017). Increasing wealth inequality may increase interpersonal hostility: The relationship between personal relative deprivation and aggression. The Journal of Social Psychology, 157(6), 766-776.

18. Sherman, E. (2018, February 10). Women Make Less as Uber Drivers and That's Bad News for the Gig Economy. Forbes. Retrieved from www.forbes.com/sites/eriksher man/2018/02/10/women-make-less-as-uber-drivers-and-thats-bad-news-for-the-gigeconomy/\#98de31f560ec.

19. Smith, H., Pettigrew, T., Pippin, T., \& Bialosiewicz, S. (2012). Relative Deprivation: A Theoretical and Meta-Analytic Review. Personality and Social Psychology Review, 16(3) 203-232.

20. Spradley, J. (1979). The ethnographic interview. New York: Holt, Rinehart \& Winston.

21. Stouffer, S. A., Suchman, E. A., DeVinney, L. C., Star, S. A., \& Williams, R. M., Jr. (1949). The American Soldier: Vol. 1. Adjustment during Army Life. Princeton: Princeton University Press.

22. The Social Issues Research Centre. (2004). Sex differences in Driving and Insurance Risk. Oxford: SIRC.

23. Van Zyl, G. (2016, July 18). Exclusive: Cape Town Clamps Down On Uber, Impounds 300 Cars. Fin24Tech. Retrieved from https://www.fin24.com/Tech/News/exclusive-capetown-clamps-down-on-uber-impounds-300-cars-20160718.

24. Zilmann, D. (1971). Excitation transfer in communication-mediated aggressive behaviour. Journal of Experimental Social Psychology, 7, 419-434. 